\title{
Congenital Hemothorax in a Preterm Neonate
}

\section{Asad Rahman}

College of Medicine and Health Sciences, Sultan Qaboos University, Al Khoudh,Muscat 123, Oman

\section{Abstract}

Congenital idiopathic pleural effusion is a very rare condition in neonates. Majority of the congenital pleural effusion are associated with documented cause such as hydrops fetalis, chromosomal causes, cardiac or pulmonary causes. The congenital effusion is mostly transudate, exudates or chylous. Hemorrhagic pleural effusion without any documented coagulation abnormality is rare. We are reporting a case of unilateral hemorrhagic pleural effusion in a preterm neonate.

\section{Publication History:}

Received: February 01, 2016

Accepted: May 12, 2016

Published: May 14, 2016

\section{Keywords:}

Asthma, Corticosteroids, Infantile wheezing, Otitis media, Sinusitis

\section{Introduction}

There is very limited data available about congenital neonatal pleural effusion. Two studies have reported the incidence of neonatal pleural effusion between 0.06-2.2 percent [1,2]. The incidence of isolated congenital pleural effusion is about 1 in 12,000 to 1 in 15,000 deliveries [3]. Multiple causes have been associated with congenital pleural effusion. Majority of these disorders present with hydrops fetalis and bilateral pleural effusion. The content of pleural effusion is transudate, exudates or chylous. Hemorrhagic pleural effusion or hemothorax may be associated with DIC or coagulation disorder. We are reporting a preterm neonate with congenital neonatal unilateral hemothorax.

\section{Case Report}

A pretern newborn was delivered at 33 weeks of gestation by spontaneous vaginal delivery. The mother was 25 year old and was under regular antenatal follow up in our hospital. Antenatal screening was unremarkable. No abnormality was detected in antenatal ultrasound at 20 weeks of gestation. The baby was in severe respiratory distress at birth and needed intubation and positive pressure ventilation. Chest radiograph showed generalized opacity on left side and there was mediastinal shift. Ultrasound showed left sided pleural effusion and a collapsed left lung. The pleural effusion was drained with a chest tube. The analysis of pleural fluid showed hemorrhagic fluid with few lymphocytes and no atypical cells. No microorganism was seen on gram stain and there was no growth on culture. Repeat chest radiograph showed expanded lungs. There was no recollection of pleural effusion and chest tube was removed after 3 days. Hematology and pulmonalogy team was consulted and all work up for pleural effusion was within normal range. Karyotype and chromosomal analysis was normal. Baby was discharged home and being followed up in outpatient clinic.

\section{Discussion}

Congenital pleural effusion may be secondary to various disorders. In majority of cases congenital pleural effusion is associated with hydops fetalis. Isolated pleural pleural effusion may be secondary to lymphatic abnormality. Most of isolated effusion present as chylous effusion. Isolated hemorrhagic and non chylous effusions are rare. Hemorrhagic effusion may present secondary to disseminated intravascular coagulation, hemorrhagic disease of newborn or trauma [4]. Our case has normal coagulation study and there was no history of trauma. There was no recollection of pleural fluid and the baby did very well after the drainage. That rules out any lymphatic, bronchial

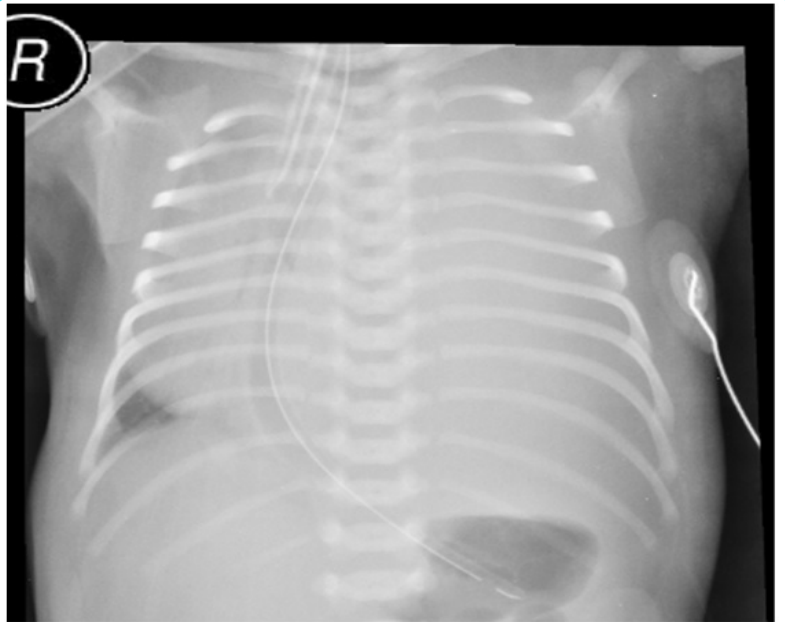

Figure 1: Chest radiograph before chest tube insertion/

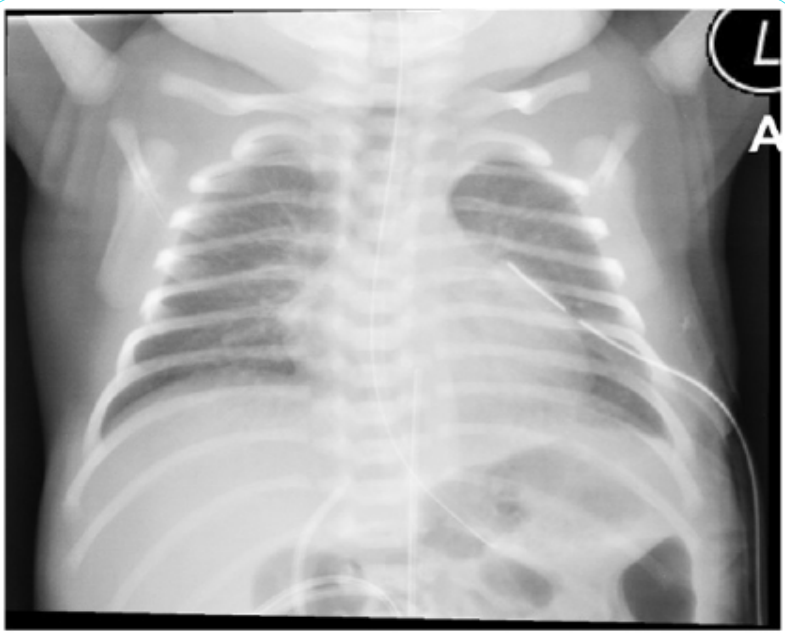

Figure 2: Repeat chest radiograph after chest tube insertion showing fully expanded lung without any residual pleural effusion.

"Corresponding Author: Dr. Asad Rahman, College of Medicine and Health Sciences, Sultan Qaboos University, Al Khoudh,Muscat 123, Oman ; E-mail: asad99khan@yahoo.com

Citation: Rahman A (2016) Congenital Hemothorax in a Preterm Neonate. Int J Pediatr Neonat Care 2: 114. doi: https://doi.org/10.15344/2455-2364/2016/114

Copyright: ( 2016 Rahman. This is an open-access article distributed under the terms of the Creative Commons Attribution License, which permits unrestricted use, distribution, and reproduction in any medium, provided the original author and source are credited. 
structural, or vascular anomalies. Congenital pleural effusion may present with severe pulmonary hypoplasia. When detected antenatally, an attempt should be made to dertemine the eitiology.

\section{Competing Interests}

The authors declare that they have no competing interests.

\section{References}

1. Rocha G, Fernandes P, Rocha P, Quintas C, Martins T, et al. (2006) Pleural effusion in neonate. Acta Paediatr 95: 791-798.

2. Long WA, Lawson EE, Hamed HS Jr, Kraybil EN (1984) Pleural effusion in the first day of life: a prospective study. Am J Perinatol 1: 190-194.

3. Longaker MT, Leberge JM, Dansereau J, Langer JC, Crombleholme TM et al. (1989) Primary fetal hydrothorax: natural history and management. J Pediatr Surg 24: 573-576.

4. Opperman HC, Wille L (1980) Hemothorax in newborn. Pediatr Radiol 9: 129-134.

5. May DA, Barth RA, Yeager S, Nussbaum-Blask A, Bulas DI (1993) Perinatal and postnatal sonography. Radiol Clin North Am 31: 499-516. 